\title{
Role of genital tract infections and inflammatory processes in male infertility
}

\section{Codruța Silea $^{1,2}$, Alina Maria Holban ${ }^{3^{*}}$, Mariana Carmen Chifiriuc ${ }^{2,3}$}

\author{
${ }^{1}$ Synevo Suceava, Suceava, Romania; Department of Microbiology, Faculty of Biology, University of Bucharest, \\ Bucharest, Romania; ${ }^{3}$ Research Institute of the University of Bucharest, Bucharest, Romania \\ $\llbracket$ Correspondence to: Alina Maria Holban, Department of Microbiology, Faculty of Biology, University of Bucharest, Aleea \\ Portocalelor No. 1-3, 060101, Bucharest, Romania E-mail: alina_m_h@yahoo.com
}

Received: 11 January 2018 / Revised: 7 June 2018 / Accepted: 15 June 2018 / Available online: 25 June 2018

\begin{abstract}
Inflammation and male genital tract infections could interfere with the spermatogenesis process and lead to damages in sperm quality, as well as to seminal tract obstruction, being thus considered two of the most important causes of male infertility. Therefore, currently, there is an acute need for a better standardization of the methodology used in the clinical practice to detect and identify microorganisms infecting the male urogenital tract and also for the correct diagnosis of inflammatory processes correlated with male infertility. This paper aims to review some of the physiological changes of the main determinants of sperm quality induced by inflammatory and infectious processes, such as increased seminal leucocytes, oxidative stress and cytokines production.
\end{abstract}

Keywords: male infertility, infection, inflammation

\section{Introduction}

Inflammation and male genital tract infections represent two of the most common causes of male infertility, which are widely investigated worldwide. Because they can induce important damages during spermatogenesis process, impair sperm quality and lead to seminal tract obstruction, such conditions should be early diagnosed, since early antibiotics and anti-inflammatory treatments may improve healing and restore fertility. Even though a relationship between infection and infertility has been postulated since 1970s, most studies to offer valid evidence on this field have been published over the last two decades (Rowe, 2000). Epidemiological studies show that male genitourinary tract infections represent $15 \%$ of infertility causes (Pellati et al., 2008). Inflammation, as well as acute and chronic infections of the male reproductive system can compromise the function of the sperm cells and the whole spermatogenetic process (Henkel et al., 1998; Sanocka-Maciejewska et al., 2005), causing qualitative and quantitative changes in sperm. Recent studies have shown that the presence of bacteria in sperm samples can compromise its quality. Seminal material contaminating bacteria generally originate from the urinary tract or may be transmitted through sexual contact (Purvis et al., 1993). These bacteria could induce a decrease in sperm quality parameters, sperm count decrease, morphological alterations, and decreased motility.

\section{Pathogenic significance of leucocytes count in the seminal fluid}

In the vast majority of sperm samples, leukocytes, predominantly neutrophils are normally present in 0.5 $10^{6} / \mathrm{ml}$ of sperm counts (Aitken et al., 1994; Aitken et al., 1998). A mild leucospermia may be also encountered (1-2 x $10^{6}$ leukocytes / $\mathrm{ml}$ sperm), while in the case of an infectious process, the leukocyte count exceeds $5 \times 10^{6} /$ $\mathrm{ml}$ (WHO 1992). A significant increase in leukospermia is thus indicative for an infectious process and this condition could highly influences fertility capacity. The leukospermia (Fig. 1) has a frequency of about $29 \%$ among infertile men. Granulocytes are the most prevalent (50-60\%), followed by macrophages (20-30\%) and $\mathrm{T}$ lymphocytes (2-5\%) (Stanislavov 1999). Immature germ cells, spermatids and sperm cells are also present in the ejaculate of most infertile men (Gonzales et al., 1992).

Seminal leucocytes have testicular origin in the epididym and prostate, and the contribution of seminal vesicles is minimal (Simbini et al., 1998). Leucospermia seems to be correlated with a decreased number and motility of the sperm, which could lead to infertility (Tolbert et al., 1987). Also it increases the number of spermatozoa with abnormal morphology (Wolff et al., 1999). 


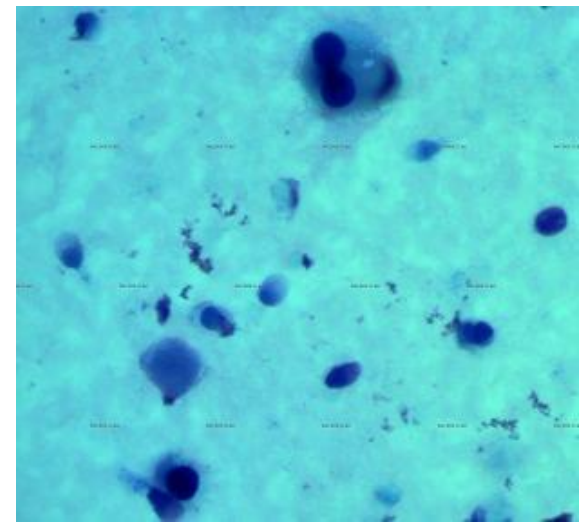

Fig. 1. Microscopic image of Giemsa stained smear from a sperm sample with leukospermia: leukocytes and spermatozoa heads with abnormal morphology and size (Carl Zeiss AxioVision Imaging System, Obj. 100X).
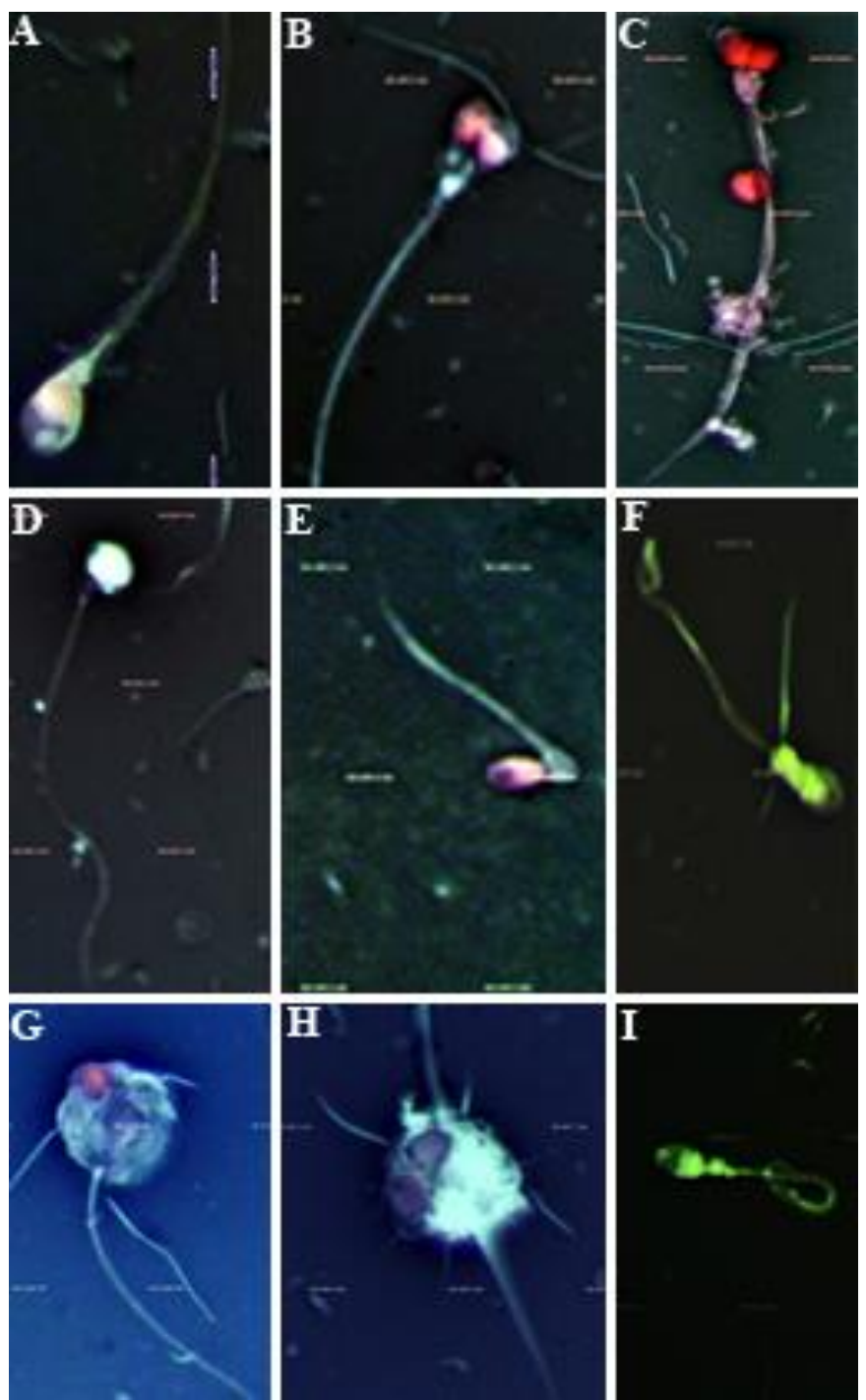

Fig. 2. Microscopy images of sperm smears stained with eosin nicrosin, containing spermatozoa with abnormal morphology: A: macrocephalous head; B: bicephalous spermatozoon; C: bicephalous spermatozoon with thick midpiece insertion and completely coiled tail; D: incomplete acrosome; E: misaligned midpiece; F: thick midpiece insertion; G: abnormal residual cytoplasm; H: bicephalous spermatozoon with and abnormal residual cytoplasm; I: coiled tail (Carl Zeiss AxioVision Imaging System, Obj. 100X).
In the seminal material, leukocytes are the main source of free radical production in the case of an inflammatory / infectious process. Seminal reactive oxygen species (ROS) production may therefore have an intrinsic origin (residing within the sperm cells), being released from sperm or extrinsic origin, being released by leukocytes (Sandra et al., 2008). Both categories can alter the DNA integrity of the sperm. Increased ROS production can cause sperm abnormalities: decreased sperm motility, acrosin activity and sperm-ovocin fusion capacity modification (Lanzafame et al., 2009). Leukocytes produce 1000 times higher amounts of ROS than sperm cells (Plante et al., 1994). A positive correlation between the number of seminal leukocytes and the amount of ROS has been reported (Aitken et al., 1994; Gomez et al., 1998; Zini et al., 2000). The release of ROS is one of the main mechanisms by which neutrophils destroy pathogens, but also have the potential to cause oxidative stress within the host cells.

Cytokines synthesized in prostate infection and inflammation, such as IL-1, IL-6, IL-8, IL12, IL-18, TNF- $\alpha$ profoundly influence the quality of seminal material (Fraczek et al., 2007) by decreasing sperm motility. Cytokines also disrupt the functions of the accessory glands. IL-1 has a higher plasma concentration in patients with infertility as compared to fertile male (Dousset et al., 1997). IL-6 has a higher concentration in seminal plasma of infertile than fertile patients and inhibits the synthesis of sperm malonaldehyde in vitro (Camejo et al., 2001). IL-8 does not influence sperm motility or in vitro acrosomal reaction. In contrast, seminal plasma IL-8 inhibits sperm motility (La Vignera et al., 2014). It has been revealed that TNF- $\alpha$ production is higher in patients with bacterial infections such as Mycoplasma sp. (Gruschwitz et al., 1996). TNF- $\alpha$ inhibits the in vitro sperm motility (Hill et al., 1987) and the ability of spermatozoa to fertilize oocytes. Prostate tissue significantly contributes to the level of cytokines in sperm secretion.

\section{Male genital tract inflammatory conditions}

Male urethra is the ascending pathway of infection access to all segments of the genitourinary tract, which are normally sterile. This sterile condition is ensured by micturition and ejaculation and, in particular, by the antibacterial action of a zinc containing polypeptide eliminated by the prostatic secretion (Azenabor et al., 2015) .

Urethritis, also known as urethral inflammation, is a frequent pathologic condition with various simptomatology, depending on the severity of disease. Urethritis may either be asymptomatic, or symptomatic, 
being associated with dysuria, urethral leakage, pruritus, orchialgia (long term pain in the testes, considered chronic if it persists longer than 3 months) (Tojuola et al., 2016). Urethritis is caused mainly by sexually transmitted pathogens. The diagnosis of urethritis is confirmed by highlighting a large number of polymorphonuclear leukocytes in the anterior urethra. Etiologically, diagnostically and therapeutically, urethrites are divided into two separate conditions: gonococcal (caused by Neisseria gonorrhoeae) and non-gonococcal (Al-Sweih 2012). Gonorrhea - type urethritis may develop due to infection with $N$. gonorrhoeae, but also with Chlamydia trachomatis or Ureaplasma urealyticum, which are suspected as etiological agents if the incubation period of the primary infection is greater than that of the gonococcal infection. Gonococcal and chlamydial infections have been implicated in the inflammation of the female genital tract, particularly in pelvic inflammatory disease. On the other hand, urethritis with Cryptococcus neoformans, usually favored by gonorrhoea tetracycline therapy, may occur (Moi et al., 2015).

Prostatitis is considered to be the most common urological problem in men under 50 and the third most common urological diagnosis in men over 50 years old (Nickel 1998). The overall prevalence of prostatitis worldwide is estimated to be of $14 \%$ in men over 50 years old (Mehik et al., 2000). Four types of prostatitis have been described: i) acute bacterial prostatitis, ii) chronic bacterial prostatitis, iii) chronic pelvic pain syndrome and iv) asymptomatic inflammatory prostatitis (Krieger et al., 1999). Prostatitis is plays an important role in male infertility, and efficient treatment may restore the reproductive function. Prostatitis profoundly influences the quality of sperm (Marconi et al., 2009). Bacterial prostatitis induces severe changes in sperm morphology and motility (Menkveld et al., 2003) and reduce the volume of prostate secretion (Weidner et al., 1999). Prostatitis is associated with decreased prostate excretion, including decreased citric acid, $\alpha$-glucosidase, fructose, and decreased zinc secretion (Marconi et al., 2009). Sexual dysfunctions including ejaculatory and erectile dysfunction have been also associated with prostatitis (La Vignera et al., 2012). Prostatitis is also incriminated for early ejaculation, and appropriate treatment can relieve all mentioned symptoms, and restore damaged fertility.

Epididymitis is an ascending inflammation that occurs as a result of prostatitis or urethritis. Favorable factors are local trauma, especially under bacteriuria conditions. Epididymitis is usually caused by a bacterial infection localized in the urethra, bladder, prostate, which disseminates in the epididym. The most common causes of epididymitis are sexually transmitted infections (in sexually active adults) and urinary tract infections (especially in children). Etiologically, non-specific bacterial epididymitis is frequently caused by members of the Enterobacteriaceae family, followed by pseudomonads and occasionally by Gram-positive strains. Sexually transmitted epididymitis is most frequently produced by $N$. gonorrhoeae, while systemic epididymitis is occuring in tuberculosis, blastomycosis etc. In men over 35 years of age the most common cause of acute epididymitis is the benign prostatic hypertrophy which prevents the normal urinary flow from the bladder and causes infections that spread outwardly in the epididym. Other factors that cause epididymitis are the use of urinary catheters in critical care patients. More rarely encountered is the noninfectious epididymitis that is a consequence of testicular trauma and of the use of amiodarone. Acute epididymitis is an inflammation of the epididymis that occurs in men aged 19-25 years causing pain and swelling of the scrotum. Most cases are caused by sexually transmitted infections. Major complications are chronic epididymitis, infertility and testicular abscess. Epididymitis diminishes sperm production to aspermia and necrospermia and directly correlates to infertility. Loss of spermatogenesis is associated with high folliclestimulating hormone levels (Yuan et al., 2013).

Male genital tract infections and infertility

According to the WHO, seminal fluid infection is confirmed by the presence of significant bacteriospermia (> $10^{3}$ bacteria $/ \mathrm{ml}$ ), and detection of $N$. gonorrhoeae, $C$. trachomatis, $U$. urealyticum; leucocytospermia $\left(>10^{6}\right.$ leukocytes / ejaculated $\mathrm{ml}$ ). In clinical practice, if one of the mentioned criteria is not met, most practitioners consider that seminal bacteria isolation only reflects accidental contamination (Okon et al., 2005). Since the ejaculate is a mixture of secretions derived from the urogenital tract and male accessory glands, the cultivation of seminal secretion represents an efficient method to identify the presence of bacteria in all seminal tract levels (De Francesco et al., 2011). However, in the current practice, the microbiological examination of the ejaculate can result in false - positive or - negative results, either due to the presence of commensal microorganisms (i.e. bacteria on the gland, foreskin or hands of the patient), or because of bacteria colonizing the anterior urethra epithelium (Askienazy-Elbhar 2005). In order to increase the utility of the microbiological examination of the urogenital tract in the screening of male infertility, many samples must be analyzed, i.e. ejaculate, urine, urethral secretion and ballo-preputial secretion and research should be extended to assess all possible microorganisms that can alter sperm function (La Vignera et al., 2011; Leterrier et al., 2011). Although numerous microbial species could colonize skin and mucosa and may act as opportunistic pathogens, most common microorganisms that induce loss of sperm motility and morphological defects are Escherichia coli, Staphylococcus aureus, Pseudomonas aeruginosa, Proteus mirabilis and, to a lesser extent, Mycoplasma hominis (Ali Nabi et al., 2013; Rana et al., 2016). 
Gram negative bacteria, as well as known sexually transmitted etiological agents are recognized true pathogens of the prostate, while other prostate microorganisms that are occasionally detected in the urogenital tract are considered "non-pathogenic", "opportunistic pathogens" or "occasional pathogens" (most of them are common Gram positive bacterial species, such as Enterococcus faecalis, S. aureus, $S$. epidermidis, anaerobic species) (Kriger et al., 1999). The main difficulties in the interpretation of microbiological laboratory data in spermoculture and uroculture are: the presence of contaminant microbiota, the presence of bacteriostatic or bactericidal substances in prostatic secretions and prior antibiotic treatment. The microbiological examination of seminal liquid is focussed on the following groups of microorganisms: i) Gram negative bacteria belonging to the Enterobacteriaceae family (such as E. coli, Morganella morganii, Klebsiella pneumoniae, $P$. aeruginosa, $P$. mirabilis, $P$. vulgaris); ii) Gram negative non-fermenting bacilli ( $P$. aeruginosa); iii) Gram-positive, catalase positive opportunistic microorganisms ( $S$. aureus, $S$. haemolyticus, S. epidermidis); iv) Gram positive, catalase negative opportunistic microorganisms (Ent. faecalis); v) Gram negative pathogenic strains (N. gonorrhoeae); vi) obligate intracellular bacteria (C. trachomatis); vii) Mycoplasma and Ureaplasma genera (M. hominis, $M$. genitalium, U. urealyticum, U. parvum); viii) spirochetes (Treponema pallidum); ix) anaerobic bacteria; $\mathrm{x}$ ) fungi (Candida albicans); xi) viruses: human papilloma virus (HPV), herpes simplex virus (HSV), cytomegalovirus (CMV), acquired immunodeficiency virus (HIV) (Seo et al., 2016).

Gram negative bacteria in general, but also Ent. faecalis, $U$. urealyticum and $S$. epidermidis have a negative influence on sperm motility, because bacterial cells adhere to sperm mannose receptors through their pilli and inhibit their normal function (Villegas et al., 2005).

E. coli colonizes the prostate and produces acute or chronic prostatitis and epididymitis. Prostate infection with $E$. coli stimulates the synthesis of specific antibodies to sperm components, resulting in agglutination and infertility. The presence of sperm agglutinates in the ejaculate of a patient with piospermia indicates the clear presence of an E. coli infection. E. coli infection could induce besides loss of mobility, apoptosis and sperm necrosis. Infection with Pseudomonas sp. produces a progressive decrease in sperm cells motility (Basu 2005). $S$. aureus is involved in primary infertility of both men and women (Momoh et al., 2011). It was isolated from $68.2 \%$ samples of infected seminal fluid in recent screening tests (Emokpae et al., 2009; Okon et al., 2005). Chronic infection with the opportunistic pathogen $S$. aureus damages sperm fertilization capacity. However, most clinicians still consider it to be an unharmful contamination because sperm that passes through the genital tract is currently contaminated with Gram positive strains (staphylococci, streptococci and dipteroids).
Recent studies reported that Ent. faecalis is responsible for about $53 \%$ cases of sperm infection, Micrococcus sp. from $20 \%$ and $\alpha$-hemolytic streptococci from $16 \%$ of infected sperm samples. The increased presence of urogenital tract infections caused by Ent. faecalis is associated with compromising the quality of sperm, its density and morphology of the cells. The presence of $\alpha$ hemolytic micrococci and streptococci does not appear to exert any adverse effect on the quality of the sperm. Although no significant effect of enterococci on sperm motility has been observed, some researchers have reported a negative influence on the membrane integrity of the spermatozoa head, neck and mid-region, possibly mediated by hemolysin, a virulence factor of enterococci. Streptococcus sp. is the etiological agent of nongonococcal urethritis and epididymitis (Kim et al., 2017). $N$. gonorrhoeae is an important agent of sexually transmitted infections. It produces urogenital tract infection - simple gonococcal infection, colonization of urethral mucosa in man (urethritis), and endocervix and urethra in women (urethritis, cervicitis). N. gonorrhoeae is the second major cause of urethritis after $C$. trachomatis. Gonococcal urethritis has several clinical forms. Over $70 \%$ of infections have acute evolution, with marked dysuria and frequent purulent urethral discharge, and approximately $5-10 \%$ of cases develop inapparently. Untreated gonorrhoea leads to complications (canal and lymphatic spread to the prostate and epididym) and sequelae (i.e. urethral strictures) may occur. The infection can be generalized (systemic) by blood, and the joints can also be affected. After infection, immunity is not protective, and repeated infections are common. The absence of protective immunity is due both to the antigenic heterogeneity of the infectious agent and to the short half-life of antibodies in mucosal secretion (Chifiriuc et al., 2011). C. trachomatis is the common agent of sexually transmitted infections with a similar prevalence in males and females (Brunham et al., 2005). The infection may be asymptomatic (subclinical) or induces inflammatory response (Brunham et al., 2009). There are 15 serological variants, all involved in human pathology, which is very diverse, including trachoma, venerian lymphogranulomatosis (Nicolas Favre's disease) with tropism for the lymphatic system, acute urethral syndrome, bartolinitis, endometritis, salpingitis, pelvic inflammatory disease, ectopic pregnancy, infertility, perihepatitis, neonatal pneumonia and rarely vaginal, pharyngeal and neonatal enteric infections. In men especially acute urethritis can lead to chronic urethritis, prostatitis, epididymitis, Reiter's syndrome, infertility (Synevo 2010). Among infertile men there is a variation in $C$. trachomatis infection rate ranging from $0-90.3 \%$. The prevalence of Chlamydia infection is however underestimated due to its asymptomatic behaviour (Senior, 2012), being estimated to be present in up to $75 \%$ in women and $50 \%$ in males, resulting in repeated transmissions (Cunningham, et al., 2008). Ejaculate testing for $C$. trachomatis is a relatively recent concept 
and currently there is no approved methodology, the role of seminal testing being unknown. The presence of $C$. trachomatis in seminal material is believed to indicate an upper genital tract infection (Eggert-Kruse et al., 1997; Gdoura et al., 2008; Kokab., et al., 2010; Gallegos-Avila et al., 2008). The main localization of Chlamydia infection is urethra (Mulcahy et al., 1987) with subsequent evolution in epididym and testis (Trojian et al., 2009). The presence of the microorganism in urethral specimens, but its absence in seminal samples indicates an asymptomatic lower tract infection with less relevance to fertility. However, positive chlamydial DNA tests in seminal and negative chlamydial DNA samples in urethral samples indicate that the infectious agent is located in the male secretory glands, serving as an indicator for invasive infection (Wolff et al., 1994). Urogenital infection with Chlamydia induces IgG and serum IgA synthesis, which persists for years (Puolakkainen et al., 1986). IgA and IgG anti-Chlamydia in the male serum are associated with decreased quality of seminal material (Cengiz et al., 1997; Joki-Korpela et al., 2009). Asymptomatic infection with Chlamydia may be the cause of unexplained infertility (Greendale et al., 1993). The presence of anti-C. trachomatis IgA correlates with lipid peroxidation in the sperm membrane (Segnini et al., 2003). C. trachomatis lipopolysaccharides induce sperm necrosis (Hosseinzadeh et al., 2003). Chlamydiainfected spermatozoa have different nuclear changes, including chromatin structure, microdeletions, chromosomal rearrangements, aneuploids and DNA fragmentation (Hosseinzadeh et al., 2003). Chlamydia is more frequently isolated in young patients compared to $M$. genitalium (Jensen et al., 2004). Rarely the two species coexist in an infectious process (Moi et al., 2009). In $30-80 \%$ of cases with non-gonococcal urethritis none of these microorganisms are detected. In heterosexual men under 35 years old, acute epididymitis is caused by Chlamydia sp. or $N$. gonorrhoeae, with orchitis and prostatitis leading to damage to the canicular system, testicular atrophy and obstructive azoospermia (Gallegos et al., 2008; Stephens et al., 2011). Epididymis has a role in functional sperm maturation, and infection with these microorganisms influences the sperm quality (Greendale et al., 1993). In the case of chronic prostatitis, the infection leads to decreased motility, density, and morphological changes of spermatozoa (Eley et al., 2005).

Ureaplasma is a component of the normal microbiota, in $70 \%$ of sexually active individuals, males and females, being usually commensal to the inferior genital tract mucosa, and their presence is not associated with clinical manifestations (Dorobăt 2006). They could contaminate the semen during ejaculation. Of the total nongonococcal urethritis, $20-25 \%$ are caused by $M$. hominis, $U$. urealyticum and $M$. genitalium. These agents colonize the vagina of women who have contact with several partners. In the in vitro fertilization systems, the presence of $U$. urealyticum in either the seminal material or the female genital tract leads to an increase in the failure rate (Montagut et al., 1991; Reichart et al., 2000). Ureaplasmas are also etiological agents of male infertility (Radhonane et al., 2007). U. urealyticum was detected in $76 \%$ of sperm samples of men with unexplained infertility (Emokpae et al., 2009). The mechanism by which this pathogen damages the quality of sperm is not known however the spermatozoids immobilization has been demonstrated (Lee et al., 2013).
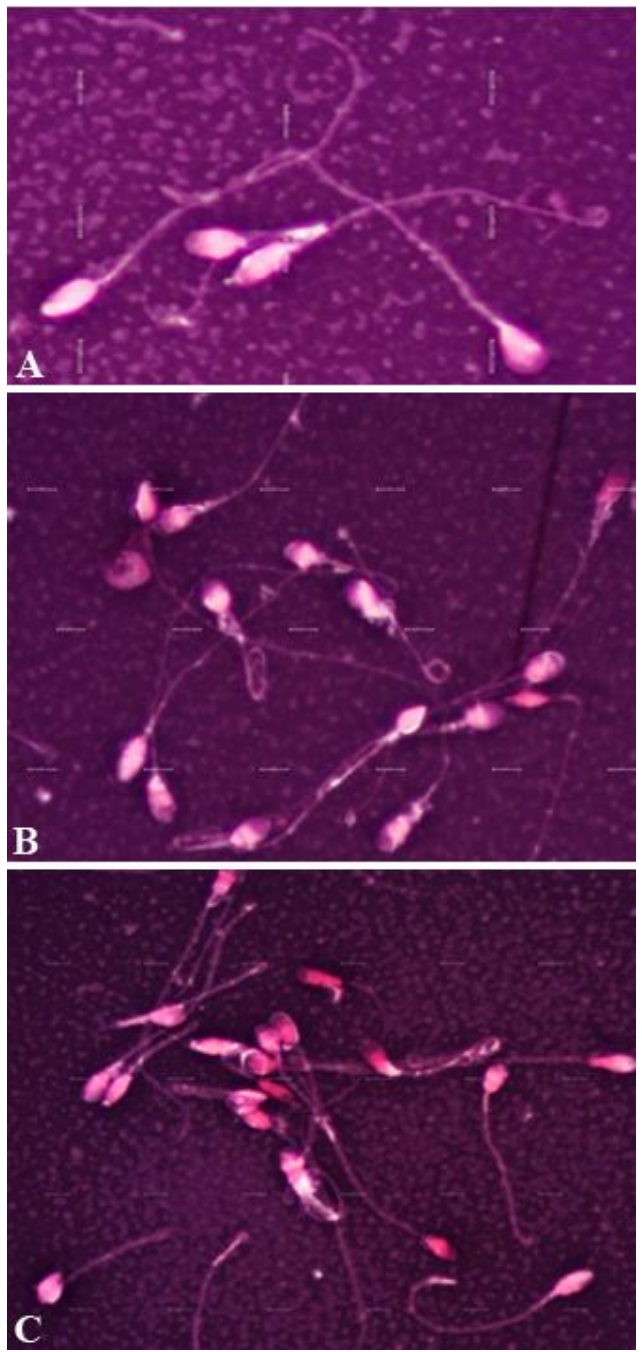

Fig. 3. Microscopy images of sperm smears stained with eosin nicrosin. A: isolate agglutination; B: moderate agglutination; C: intensive agglutination (Carl Zeiss AxioVision Imaging System, Obj. 100X).

M. hominis has been associated with bacterial vaginosis, pelvic inflammatory disease, post-partum fever and postabdominal fever and a number of other severe gynecological disorders (Yoshida et al., 2003). However, the role of $M$. hominis in the etiology of non-gonococcal urethritis and infertility is rarely investigated (Pannekoek et al., 2003). M. genitalium can be isolated from the urethral specimens of men with non-gonococcal urethritis, but its role in the development of nongonococcal urethritis is not established due to the difficulty of isolation (Jensen et al., 2004). The role of $T$. 
pallidum in infertility is unclear, but it is well known that it diminishes sperm motility and causes agglutination (Antal et al., 2002) (Fig. 3).

\section{Conclusions}

Inflammation and / or infection of male auxiliary sexual glands have a strong influence on male fertility. Clinicians should be aware of the physiological changes of the main determinants of sperm quality induced by seminal leucocytes, oxidative stress and cytokines. In addition, there is an acute need for a better standardization of the methodology used in clinical practice to detect and identify microorganisms infecting the male urogenital tract, which cause severe health conditions and are responsible for high infertility risks. Large cohort studies are required in order to establish statistically significant correlations between different infections and the sperm quality parameters, while indepth research is needed to unravel the intimate mechanisms by which different microbial components affect the sperm quality.

(OThe Author(s) 2018

Open Access This article is distributed under the terms of the Creative Commons Attribution 4.0 International License (http://creativecommons.org/licenses/by/4.0/) which permits unrestricted use, distribution, and reproduction in any medium, provided you give appropriate credit to the original author(s) and the source, provide a link to the Creative Commons license, and indicate if changes were made.

\section{References}

Al-Sweih N.A., Al-Fadli A.H., Omu A.E., Rotimi V.O. 2012. Prevalence of Chlamydia trachomatis, Mycoplasma hominis, Mycoplasma genitalium, and Ureaplasma urealyticum infections and seminal quality in infertile and fertile men in Kuwait. $J$. Androl., 33,1323-1329.

Ali Nabi B.S., Khalili M.A., Halvaei I., Ghasemzadeh J., Zare E. 2013. Seminal bacterial contaminations: Probable factor in unexplained recurrent pregnancy loss. Iran. J. Reprod. Med.. 11, 925-932.

Aitken R., Krausz C., Buckingham, D. 1994. Relationships between biochemical markers for residual sperm cytoplasm, reactive oxygen species generation and the presence of leucocytes and precursor germ cells in human sperm suspensions. Mol. Reprod. Develop. 39, 268-279.

Aitken R., Gordon E., Harkiss D., Twigg, I. 1998. Relative impact of oxidant stress on the functional competence and genomic integrity of human spermatozoa. Biol. Reprod. 59,1037-1046.

Antal G., Lukehart S. and Meheus A. 2002. The endemic treponematoses. Microb. Infect. 4, 83-94.
Askienazy-Elbhar M. 2005. Male genital tract infection: the point of view of the bacteriologist. Gynecol. Obstet. Fertil. 33, 691-697.

Azenabor A., Oloruntoba Ekun A., Akinloye O. 2015. Impact of Inflammation on Male Reproductive Tract. $J$. Reprod. Infertil. 16, 123-129.

Basu S.C. 2005. Male reproductive dysfunction. New Delhi: Jaypee Brothers, Medical publishers.

Brunham R.C., Rekart M.L. 2009. Considerations on Chlamydia trachomatis disease expression. FEMS Immunol. Med. Microbiol. 55, 162-166.

Brunham R.C., Rey-Ladino. 2005. Immunology of Chlamydia infection: implications for a Chlamydia trachomatis vaccine. Nature Rev. Immunol. 5, 149-161.

Camejo M.I., Segnini A., Proverbio F. 2001. Interleukin6 (IL-6) in seminal plasma of infertile men, and lipid peroxidation of their sperm. Arch. Androl. 47, 97-101.

Cengiz T., Aydoganli L., Baykam M., Mungan N.A.,Tuncbilek E., Dincer E., Yakupoglu K., Akalin Z. 1997. Chlamydial infections and male infertility. Int. Urol. Nephrol. 29, 687-693.

Chifiriuc C., Mihăescu Gr., Lazăr 2011. Microbiology and medical virology, Bucharest: University of Bucharest Publishing House.

Cunningham K.A., Beagley K.W. 2008. Male genital tract chlamydial infection: implications for pathology and infertility. Biol. Reprod. 79, 2180-2189.

De Francesco M. A., Negrini R., Ravizzola G., Galli P., Manca N. 2011. Bacterial species present in the lower male genital tract: a fiveyear retrospective study. Eur. J. Contracept. Reprod. Health Care. 16, 47-53.

Dousset B., Hussenet F., Daudin M., Bujan L., Foliguet B., Nabet P. 1997. Seminal cytokine concentrations (IL-1beta, IL-2, IL- 6, sR IL-2, sR IL-6), semen parameters and blood hormonal status in male infertility. Hum. Reprod. 12, 1476-1479.

Dorobăț O. 2006. Medical Bacteriology, Bucharest: Titu Maiorescu University Publishing House.

Eggert-Kruse W., Rohr G., Ströck W., Pohl S., Schwalbach B., Runnebaum B. 1995. Anaerobes in ejaculates of subfertile men. Hum. Reprod. Update. 1, 462-78.

Eggert- Kruse W., Gerhard R., Demirakca T., Rusu R., Naher H., Petzoldt D., Runnebaum B.1997 Chlamydial serology in 1303 asymptomatic subfertile couples. Hum. Reprod. 12, 1464-1475.

Eley A., Hosseinzadeh S., Hakimi H., Geary I, Pacey A.A. 2005. Apoptosis of ejaculated human sperm is induced by co-incubation with Chlamydia trachomatis lipopolysaccharide. Hum. Reprod. 20, 2601-2607.

Emokpae M.A., Uadia P.O., Sadiq N.M. 2009. Contribution of bacterial infection to male infertility in nigerians. J. Health Allied Sci. 8, 1-5.

Fraczek M., Kurpisz M. 2007. Inflammatory mediators exert toxic effects of oxidative stress on human spermatozoa. J. Androl. 28, 325-333.

Fraczek M., Piasecka M., Gaczarzewicz D., SzumalaKakol A., Kazienko A., Lenart S. 2012. Membrane 
stability and mitochondrial activ-ity of humanejaculated spermatozoa during in vitro experimental infection with Escherichia coli, Staphylococcus haemolyticus and Bacteroides ureolyticus. Andrology. 44, 315-329.

Gdoura R., Kchaou W., Ammar-Keskes L., Chakroun N., Sellemi A. Znazen A., Rebai T., Hammami A. 2008. Assessment of Chlamydia trachomatis, Ureaplasma urealyticum, Ureaplasma parvum, Mycoplasma hominis, and Mycoplasma genitalium in semen and first void urine specimens of asymp.tomatic male partners of infertile couples. J. Androl. 29, 198-206.

Gallegos J.G., Ramos B., Santiso R., Goyanes V.,Gosalvez J., Fernandez J.L. 2008. Sperm DNA fragmentation in infertile men with genitourinary infection by Chlamydia trachomatis and Mycoplasma. Fertil. Steril. 90, 328-334.

Gallegos-Avila G., Ortega-Martínez M., RamosGonzález B.,Tijerina-Menchaca R., Ancer-Rodríguez J., Jaramillo-Rangel G. 2009. Ultrastructural findings in semen samples of infertile men infected with Chlamydia trachomatis and mycoplasmas. Fertil. Steril. 91, 915-919.

Gomez E., Irvine D. Aitken R. 1998. Relationship between semen quality and sperm function. Int. J. Andrology. 21, 81-94.

Gonzales G., Kortebani G., Mazzolli A. 1992. Leukocytospermia and function of seminal vesicles on seminal quality. Fertil. Steril. 57, 1058-1065.

Greendale G.A., Haas S.T., Holbrook K., Walsh B., Schachter J., Phillips R.S. 1993. The relationship of Chlamydia trachomatis infection and male infertility. Am. J. Pub. Health. 83, 996-1001.

Gruschwitz M. S., Brezinschek R., Brezinschek H. P. 1996. Cytokine levels in the seminal plasma of infertile males. J. Androl. 17, 158-163.

Henkel R., Schill W.B. 1998. Sperm separation in patients with urogenital infections. Andrology. 30, 9197.

Hill J. A., Haimovici F., Politch J. A., Anderson D. J. 1987. Effects of soluble products of activated lymphocytes and macrophages (lymphokines and monokines) on human sperm motion parameters. Fertil. Steril. 47, 460-465.

Hosseinzadeh S., Pacey A.A., Eley A. 2003. Chlamydia trachomatis-induced death of human spermatozoa is caused primarily by lipopolysaccharide. J. Med. Microbiol. 52, 193-200.

Jensen J.S., Bjornelius E., Dohn B., Lidbrink P. 2004. Comparison of first void urine and urogenital swab specimens for detection of Mycoplasma genitalium and Chlamydia trachomatis by polymerase chain reaction in patients attending a sexually transmitted disease clinic. Sex. Transm. Dis. 31, 499-507.

Joki-Korpela P., Pahrakorpi N., Halttunen M., Surcoel H., Paavonen, Tiitinen A. 2009. The role of Chlamydia trachomatis infection in male infertility. Fertil. Steril. 91, 1448-1450.
Joyner J.L., Douglas J.M., Ragsdale S., Foster M., Judson F.N. 2000. Comparative prevalence of infection with Trichomonas vaginalis among men attending a sexually transmitted diseases clinic. Sex. Transm. Dis. 27, 236-240.

Kokab A., Mohammad M., Akhondi Mohammad R., Sadeghi Mohammed H., Modarresi Mohsed Aarabi, Roi Jennings, Allan A., Pacey A., Eley. 2010. Raised inflammatory markers in semen from men with asymptomatic chlamydial infection. J. Androl. 31, 114-120.

Kim S.J., Paik D.J., Lee J.S., Lee H.S., Seo J.T., Jeong M.S., Lee J.H., Park D.W., Han S., Lee Y.K., Lee K.H., Lee I.H., So K.A., Kim S.A., Kim J., Kim T.J. . 2017. Effects of infections with five sexually transmitted pathogens on sperm quality. Clin. Exp. Reprod. Med. 44, 207-213.

Krieger J.N., Nyberg Jr., L., Nickel J.C. 1999. NIH consensus definition and classification of prostatitis. JAMA. 282, 236-237.

Lanzafame F. M., La Vignera S., Vicari E., Calogero A. E. 2009. Oxidative stress and medical antioxidant treatment in male infertility. Reprod. Biomed. Online. 19, 638-659.

La Vignera S., Condorelli R.A., Vicari E., D’Aagata R., Salemi M., Calogero A.E. 2012a. Hyperviscosity of semen in patients with male accessory gland infection: direct measurement with quantitative viscosimeter. Andrology. 44, 556-559.

La Vignera S., Condorelli R., Vicari E., D’Agata R., Calogero A.E. 2012b. High frequency of sexual dysfunction in patients with male accessory gland infections. Andrology. 44, 438-446.

La Vignera S., Vicar E., Condorell R. A., D'Agata R., Calogero A. E. 2011. Male accessory gland infection and sperm parameters (review). Int. J. Androl. 34, 330 347.

La Vignera S., Condorelli R.A., Vicari E., Salmeri M., Morgia G., Favilla V., Cimino S., Calogero A.E. 2014. Microbiological investigation in male infertility: a practical overview. J. Med. Microbiol. 63, 1-14.

Lee J.S., Kim K.T., Lee H.S., Yang K.M., Seo J.T., Choe J.H. 2013. Concordance of Ureaplasma urealyticum and Mycoplasma hominis in infertile couples: impact on semen parameters. Urology. 81, 1219-1224.

Leterrier M., Fre' our T., Guillouzouic A., Juvin M. E., Barriere P., Reynaud A., Corvec S. 2011. Semen cultures analysis: retrospective study during a 6-year period and interest in the management of infertility. Eur. J. Clin. Microbiol. Infect. Dis. 30, 401-406.

Marconi M., Pilatz A., Wagenlehner F., Diemer T., Weidner W. 2009. Impact of infection on the secretory capacity of the male accessory glands. Int. Braz. J. Urol. 35, 299-308.

Mehik A., Hellstrom P., Lukkarinen O., Sarpola A., Jarvelin M., 2000. Epidemiology of prostatitis in Finnish men: a population-based cross-sectional study. BJU Int. 86, 443-448. 
Menkveld R., Huwe P., Ludwig M., Weidner W. 2003. Morphological sperm alternations in different types of prostatitis. Andrology. 35, 288-293.

Moi H, Reinton N, Moghaddam A. 2009. Mycoplasma genitalium in women with lower genital tract inflammation. Sex. Transm. Infect. 85, 4-10.

Moi H., Blee K., Horner P.J. 2015. Management of non-gonococcal urethritis. BMC Infect. Dis. 15, 294.

Montagut J.M., Lepretre S., Degoy J., Rousseau M. 1991. Ureaplasma in semen and IVF. Hum. Reprod. 6, 727-729.

Momoh A.R.M., Idonije B.O., Nwoke E.O. 2011. Pathogenic bacteria-a probable cause of primary infertility among couples in Ekpoma. J.Microbiol. Biotech. Res. 1, 66-71.

Mulcahy F.M., Bignell C.J., Rajakumar R. 1987. Prevalence of chlamydial infection in acute epididymoorchitis. Genitourin. Med., 63, 16-18.

Nickel J.C. 1998. Prostatitis: myths and realities. Urology. 51, 362-366.

Okon K.O., Nwaogwu M., Zailani S.O., Chama C. 2005. Pattern of Seminal fluid indices among infertile Male partners attending the infertility clinic of University of Maiduguri Teaching Hospital, Maiduguri, Nigeria. Highland Med. J., 1, 18-23.

Pannekoek Y., Westenberg S.M., Eijk P.P., Repping S., Fulco van der Veen, van der Ende A., Dankert J., 2003. Assessment of Chlamydia trachomatis infection of semen specimens by ligase chain reaction. J. Med. Microbiol. 52, 777-779.

Park H.R., Kim Y.H., Lee H.J., Oh J.S., Kim H.J. 2006. Usefulness of the MYCOFAST test (MYCOFAST ${ }^{\circledR}$ Evolution 2) for the diagnosis of non-gonococcal genitourinary infections. Korean J. Urol.47,11171123.

Pellati D., Mylonakis I., Bertoloni G., Fiore C., Andrisani A., Ambrosini G., Armanini D. 2008. Genital tract infections and infertility. Eur. J. Obstet. Gynecol. Reprod. Biol. 140, 3-11.

Plante M., Lamirande E., Gagnon C. 1994. Reactive oxygen species released by activated neutrophils, but not by deficient spermatozoa, are sufficient to affect normal sperm motility. Fertil. Steril. 62, 387-393.

Puolakkainen M., Vesterinen E., Purola E., Saikku P., Paavonen J.1986. Persistence of chlamydial antibodies after pelvic inflammatory disease. J. Clin. Microbiol. 23, 924-928.

Purvis K., Christiansen E. 1993. Infection in the male reproductive tract. Impact, diagnosis and treatment in relation to male infertility. Int. J. Androl. 16, 1-13.

Radhouane G., Wiem K., Chiraz C., Abir Z., Leila K., Tarek R., Hammami A.. 2007. Ureaplasma urealyticum, Ureaplasma parvum, Mycoplasma hominis and Mycoplasma genitalium infections and semen quality of infertile men. BMC Infect. Dis. 7, 129. http://doi.org/10.1186/1471-2334-7-129.

Rana K., Vander H., Bhandari P., Thaper D., Prabha V. 2016. Microorganisms and Male Infertility: Possible
Pathophysiological Mechanisms. Adv. Clin. Med. Microb. 1, 1-10,

Reichart M., Kahane I., Bartoov B. 2000. In vivo and in vitro impairment of human and ram sperm nuclear chromatin integrity by sexually transmitted Ureaplasma urealyticum. Infect. Biol. Reprod. 63, 1041-1048.

Rowe P.J. 2000. WHO manual for the standardized 1nvestigation, diagnosis and management of the infertile male, Cambridge: Cambridge University Press.

Sandra L.,Vignera A., Calogero A., Alessandro A., Roberto C. 2008. Transrectal ultrasonography in infertile patients with persistently elevated bacteriospermia. Asian J. Androl. 10, 731-740.

Sanocka-Maciejewska D., Ciupińska M., Kurpisz M. 2005. Bacterial infection and semen quality. J Reprod Immunol. 67, 51-56.

Segnini A., Camejo M.I., Proverbio F. 2003. Chlamydia trachomatis and sperm lipid peroxidation in infertile men. Asian J. Androl. 5, 47-49.

Senior K. 2012. Chlamydia: a much underestimated STI. The Lancet Infect. Dis. 12, 517-518.

Seo H.H., Kim Y.J., Jeong M.S., Hong S.R., Lee I.H., So K.A., Kim M.K., Lee K.L., Lee K.H., Kim J., Kim S.J., Kim T.J. 2016. Combined SYBR green real-time polymerase chain reaction and microarray method for the simultaneous determination of human papillomavirus loads and genotypes. Obstet. Gynecol. Sci. 59:489-497.

Shahmanesh M.1994. Problems with non-gonococcal urethritis. Int. J. STD. 5, 390-399.

Simbini T., Umapathy E., Jacobus E., Tendaupenyu G., Mbizvo M. 1998. Study on the origin of seminal leukocyte using split ejaculation technique and the effect of leukocy to spermia on sperm characteristics. Urol. Int. 61, 95-100.

Stanislavov R. 1999. Leukocyte in human seminal fluid. Akush. Ginekol. 38, 20-21.

Stephens A.J., Aubuchon M., Schust D.J. 2011. Antichlamydial antibodies, human fertility, and pregnancy wastage. Infect. Dis. Obstet. Gynecol.11, 525152, doi: 10.1155/2011/525182

Synevo Laboratory. 2010. Medical Guide, 3, 543-551.

Talbert L., Hammond M.G., Halme J., Oi-Rand M., Fryer J., Ekstron R. 1987. Semen parameters and fertilization of human oocyte in vitro: amultivariable analysis. Fertil. Steril. 84, 270-277.

Tojuola B., Layman J., Kartal I., Gudelogul A., Brahmbhatt J., Parekattil S. 2016. Chronic orchialgia: Review of treatments old and new. Indian J. Urol. 32, 21-26.

Trojian T., Lishnak T., Heiman D. 2009. Epididymitis and orchitis: An overview. Am. Fam. Physician, 79, 583-587.

Villegas J., Schulz M., Soto L., Sanchez R. 2005. Bacteria induce expression of apoptosis in human spermatozoa. Apoptosis. 10, 5-10. 
Weidner W., Ludwig M., Brahler E., Schiefer H.G. 1999a. Outcome ofantibiotic therapy with ciprofloxacin in chronic bacterial prostatitis. Drugs. 58, 103-106.

Wolff H., Politch J., Martinez A., Haimorici F., Hill J., Anderson D. 1999. Leukocytospermia is associated with poor semen quality. Fertil. Steril. 53, 528-536.

Wolff H., Neubert U., Volkenandt M., Zochling N., Schupen E.M., Bezold G., Meurer M. 1994.

Detection of Chlamydia trachomatis in semen by antibody-enzyme immunoassay compared with polymerase chain reaction, antigen-enzyme immunoassay, and urethral cell culture. Fertil. Steril. $62,1250-1254$.

World Health Organization (WHO). 1992. Laboratory manual for the examination of human semen and sperm-cervical mucus interaction. Cambridge: Cambridge University Press.

Yoshida T., Maeda S., Deguchi T., Miyazawa T., Ishiko H. 2003. Rapid detection of Mycoplasma genitalium by PCR-microtiter plate hybridization assay. J. Clin. Microbiol. 41, 1850-1855.

Yuan S., Zheng H., Zheng Z., Yan W. 2013. Proteomic analyses reveal a role of cytoplasmic droplets as an energy source during epididymal sperm maturation. Plos One 8, e77466.

Zini A., Garrels K., Phang D. 2000. Antioxidant activity in the semen of fertile and infertile men. Urology. 55, 922-927. 